\title{
Prevalence of Indeterminate Human Immunodeficiency Virus Western Blot Results in Pregnant Women Attended at a Public Hospital in Presidente Prudente, Brazil
}

\author{
Denise Cremonezi ${ }^{1}$, Paulo Eduardo de Mesquita ${ }^{1}$, \\ Marisa Menezes Romão ${ }^{2}$ and Luiz Euribel Prestes-Carneiro ${ }^{1}$
}

Department of Infection Diseases and Department of Immunology, Universidade do Oeste Paulista (UNOESTE)'; Adolfo Lutz Institute ${ }^{2}$; Presidente Prudente, SP, Brazil

\begin{abstract}
The AIDS epidemic is spreading rapidly among women worldwide, offering increasing opportunities for vertical transmission of HIV. In Brazil, the prevalence of HIV infection among pregnant women is less than $1 \%$. Therefore, the positive predictive value of an HIV EIA test tends to be lower than the more frequent indeterminate Western blot result. Pregnant women receiving antenatal care, from 2000 to 2004, at a public secondary hospital in the city of Presidente Prudente, São Paulo, Brazil, were systematically screened for HIV by means of two distinct EIA tests, in order to determine the prevalence of indeterminate Western blot results among pregnant women showing discordance in both HIV EIA tests and indirect immunofluorescence assay. Confirmatory indirect immunofluorescence was performed on material for all women with positive results in both EIA tests. Whenever there were positive results in EIA and IIA, the applicant was retested by the initial screening assay. Only those not showing concordance in results in EIA and IAA had a Western blot performed. The viral load was measured in pregnant women with positive or indeterminate Western blot results. Out of 9,786 sera, $105(1.0 \%)$ were positive in the two HIV EIA screening tests, confirmed by indirect immunofluorescence. Among these women, Western blot was interpreted as indeterminate in $11(0.1 \%)$ cases and their viral load was $<50$ copies $/ \mathrm{mL}$. We found a prevalence of 0.1\% HIV indeterminate Western blots in pregnant women from Presidente Prudente and the surrounding region; none of these pregnant women had positive HIV viral loads.

Key Words: HIV-1, indeterminate Western blot, pregnant women.
\end{abstract}

According to the World Health Organization (WHO), the AIDS epidemic is affecting women in increasing numbers, particularly in Eastern Europe, Asia and Latin America. Most of the infected women are at reproductive age, especially the young ones, aged 15-24 years [1]. Initially restricted to large urban centers, involving predominantly the masculine

Received on 3 June 2005; revised 17 October 2005.

Address for correspondence: Dr. Luiz Euribel Prestes Carneiro.

Rua José Bongiovani 700. Laboratório de Imunologia Clínica

- Universidade do Oeste Paulista, Presidente Prudente, São

Paulo, Zip code: 19050-900. Phone (55 18)229-1084/229-1189.

Fax: (55 18) 229-2080. E-mail: luiz@unoeste.br

Supported by Pró-Reitoria de Pesquisa e Pós-Graduação da UNOESTE.

The Brazilian Journal of Infectious Diseases 2005;9(6):506-509 (C) 2005 by The Brazilian Journal of Infectious Diseases and Contexto Publishing. All rights reserved. gender, the infection now spreads rapidly in Brazil among heterosexuals, and among poor people and women. In some regions, the gender ratio of infection is already one man to one woman. Consequently, pediatric infection from mother-to-child transmission is the most common route of HIV infection among Brazilian children, although the prevalence of HIV infection among pregnant women in Brazil is less than $1 \%$ [2-3].

There is an effort on the part of the Brazilian public health policies to increase antenatal counseling, offering HIV testing to all pregnant women, and improving subsequent management of patients with positive results. Lately, vertical transmission has been reduced due to administration of Zidovudine to HIVinfected women during pregnancy and birth, as well as to the newborns [4-5]. 
The first step in HIV testing in pregnant women is a screening antibody test using the enzyme-linked immunoabsorbent assay (EIA). The third generation of EIA tests has synthetic and recombinant HIV-1 and HIV-2 specific antigens, with a specificity of $99.4 \%-$ $100 \%$, and sensitivity of $99 \%-100 \%$. Whenever the screening EIA is positive, the most widely used confirmatory test is the Western blot (WB). However, concern has been expressed about the value of HIV screening of low risk groups, such as blood donors and pregnant women [6-8].

The recommendation that all pregnant women should be tested for HIV, independent of risk behavior, has triggered a significant rise in both the percentage of false-positives from screening EIA and indeterminate findings in the confirmatory Western blot test (IWB). Therefore, the positive predictive value (PPV) of an EIA test in low risk groups tends to be lower, resulting in more frequent indeterminate Western blots. Women receiving such results are generally in emotional turmoil, in addition to the pregnancy situation. An indeterminate result can cause the same problems as when a physician misinterprets the result as being indicative of HIV infection. Physicians who provide antenatal care need to be alert to the occurrence, impact, and causes of indeterminate HIV screening and confirmatory test results [7-9].

We examined the prevalence of Indeterminate Human Immunodeficiency Virus Western blot results in pregnant women in Presidente Prudente, SP, Brazil, and in the vicinity.

\section{Material and Methods}

Pregnant women reporting to the antenatal clinic and to the delivery room at Hospital Estadual Dr. Odilo Antunes Siqueira, Presidente Prudente, Brazil, between January 2000 and November 2004, were enrolled in this study. This project was approved by the Institutional Ethics Committee.

All pregnant women sera samples were systematically screened for HIV-1/2, by means of two distinct commercial third-generation enzyme-linked immunoaborbent assays (HIV-EIA1 and HIV-EIA2), according to the algorithm defined by Government Decrees No. 488/SVS/MS and No. 59, January 2003. Indirect immunofluorescence assays (IIA) were performed on all women with positive results in EIA1 and negative or positive results in EIA2. If the sample came out positive in EIA2 and IIA, it was considered positive for HIV and the applicant was advised to submit a second blood sample to be retested by the initial screening assay. Only those sera coming out negative in EIA2 with IIA positive, or those positive in EIA2 with IIA negative, had a Western blot performed. The viral load (bDNA Assay) was assayed in patients with HIV positive or indeterminate Western blot results.

The Western blot was considered positive if the patient serum was reactive to two of the following HIV1 viral proteins: p24, gp41, and either gp120 or gp160. A confirmatory pregnant woman assay result was considered to be indeterminate for HIV-1, if the WB test showed at least one band characteristic of HIV-1 (p17, p24, p31, gp41, p51, p55, p66, gp120 or gp160), but did not meet the criteria for a positive result.

\section{Results}

One hundred and five out of 9,786 pregnant women sera $(1.0 \%)$ were positive for HIV according to the algorithm defined by the Government Decrees No. 488 and No. 59. On the other hand, 11 sera $(0.1 \%)$ positive in EIA1, negative or positive in EIA2 and negative in IAA, were indeterminate in Western blot (Table 1); p24 was the band expressed by the majority (8) of these sera. On the other hand, p18, p31, p39 and p55 appeared only once in four different sera. We had enough serum to perform the viral load test in 10 out of 11 pregnant women who had tested indeterminate by Western blot; one of the participants had moved from the region. All these pregnant women had $<50$ copies/ $\mathrm{mL}$.

The distribution of pregnant women by age group was as follows: $15-25$ years, $62.6 \%, 25-35$ years, $31.6 \%$, and $>35$ years, $5.8 \%$. The mean age for the HIV-positive group was 29 (ranging from 16 to 43), 
Table 1. Western blot bands of sera samples from 11 pregnant women screened for HIV-1/2 by EIA1 and EIA2 with negative IIA and indeterminate Western blot

\begin{tabular}{ll}
\hline No. & Western blot \\
\hline 1 & $(\mathrm{p} 24 \mathrm{gp} 160)$ \\
2 & $(\mathrm{p} 39 \mathrm{gp} 160)+$ non specific bands between p66 and gp120 \\
3 & $(\mathrm{p} 24 \mathrm{p} 31 \mathrm{p} 51 \mathrm{p} 66 \mathrm{gp} 120) \mathrm{gp} 160$ \\
4 & $\mathrm{p} 24(\mathrm{gp} 41)$ \\
5 & $(\mathrm{p} 17 \mathrm{gp} 41)+$ non specific bands between p66 and gp120 \\
6 & $(\mathrm{p} 24 \mathrm{p} 51 \mathrm{p} 55)$ \\
7 & $(\mathrm{p} 18 \mathrm{p} 24)$ \\
8 & $(\mathrm{p} 24 \mathrm{p} 66)$ \\
9 & $\mathrm{p} 24$ \\
10 & $(\mathrm{p} 24 \mathrm{p} 66 \mathrm{gp} 120)$ \\
11 & $\mathrm{p} 17(\mathrm{P} 24 \mathrm{gp} 160)$ \\
\hline
\end{tabular}

The bands in parentheses were weakly reactive.

and for the IWB was 24 (ranging from 16 to 33). In relation to ethnicity, $55 \%$ in the HIV-positive group were African-Brazilian descendents and $45 \%$ were Caucasians, and in the IWB group, $70 \%$ were AfricanBrazilian descendents and 30\% were Caucasians.

\section{Discussion}

We found a prevalence of $1 \% \mathrm{HIV}-1$ infected pregnant women living in or nearby Presidente Prudente, Brazil, and a prevalence of $0.1 \%$ of pregnant women who were considered indeterminate for HIV. All of the specimens had at least one of the bands necessary to indicate a WB-positive test, but they reacted with very low intensity. These findings are different from those reported by Alexander et al. [10] in an antenatal population of a teaching hospital in Akron, Ohio. Screening HIV antibodies by repeatedly reactive ELISA in 4,419 women, who had been submitted for rubella antibodies testing, gave an incidence of $0.09 \%(4 / 4,419)$ for HIV infected women and $0.31 \%(14 / 4,419)$ for IWB. The reasons for most HIV-1 IWB results are unknown, although they have been associated with autoantibodies, such as Rheumatoid Factor, ANAs, and antibodies to DR human lymphocyte antigens (HLA). Alloimmunization, through transfusions, transplantation, polyclonal gammopathy treatment, and pregnancy, may also play a role [7]. Pregnancy could be a risk factor for IWB, since the mother produces autoantibodies to cellular proteins that comigrate with $\mathrm{HIV}-1$ proteins on the WB [11]. Moreover, pregnant women are often multiparous, sometimes with prior history of ante-or post-partum hemorrhage, requiring transfusion, thus becoming susceptible to autoimmune diseases [9].

The frequency of IWB tests in healthy individuals at low risk for HIV-1 infection, such as blood and organ donors, and pregnant women, is higher than in individuals with relatively high risk for HIV-1 infection, such as intravenous drug users [12]. Jackson et al., [6] reported that $13 \%$ to $48 \%$ of the individuals repeatedly reactive in an HIV-1 ELISA blood donors screening had IWB-HIV-1 antibodies. Midthum et al. [12] in a trial of an AIDS vaccine candidate, screened adults with low risk for HIV-1 infection, and surprisingly found that $32 \%$ of these patients had IWB tests. However, in these studies, HIV antibodies were screened by means of first-generation EIA tests, in which partially purified viral antigens derived from whole disrupted HIV virus were obtained from infected cultured cells [13]. In this situation, a false positive result should be more 
frequently expected. Moreover, the definition of a positive Western blot was not uniform in the United States and elsewhere, and the bands pattern necessary to confirm a positive result was different from our criteria.

With the increasing effort to screen pregnant women for HIV-1 infection, more low-risk women will be tested, and IWB will increase. A patient with such a result could be advised that, in the case of a lack of symptoms or risk factors, it is very unlikely that the IWB would signify the presence of HIV-1 infection [14]. In fact, we found that none of the IWB pregnant women that we tested had a positive HIV viral load.

Most of the HIV-1 infected and the IWB pregnant women in our study were African-Brazilian descendents. Da Silva et al. [15] also found higher HIV incidence among African-Brazilians descendents, apparently linked to poverty, and to the deep inequalities that exist in Brazilian society [2]. This is a worldwide phenomenon, as Celum et al. [11] found that the prevalence of HIV-1 infection in Seattle and elsewhere was higher in black African descendents than in other ethnic groups [11-16,17].

In conclusion, we found a prevalence of $0.1 \%$ IWBHIV in pregnant women from Presidente Prudente and region and none of the 10 tested women had an HIVpositive viral load. Our data supports and extends the observations of others, that in the screening of pregnant women for HIV-1 infection, an IWB result does not suggest HIV-1 infection. Physicians who provide antenatal care should be sensitive to and prepared to properly deal with these findings.

\section{Refernces}

1. Joint United Nations Program on HIV/AIDS (UNAIDS) and World Health Organization (WHO) - AIDS Epidemic Update. UNAIDS/02.46E. December 2004. Available at: http://www.unaids.org.WAD2004/ EPI 1204 PDF em/EpiUpdate04 en.pdf Accessed on Dec. $18^{\text {th }} 2004$.

2. Brito A.M., Castilho E.A., Szwarcwald C.L. AIDS and HIV infection in Brazil: a multifaceted epidemic. Rev Soc Bras Med Trop 2001;34(2):207-17.
3. El Beitune P., Duarte G., Quintana S.M.,Figueiró-Filho E.A. HIV-1: maternal prognosis. Rev Hosp Clin Fac Med Sao Paulo 2004;59(1):25-31.

4. El Beitune P., Duarte G., Quintana S.M., et al. Antiretroviral therapy during pregnancy and early neonatal life: consequences for HIV-exposed, uninfected children. Braz J Infect Dis 2004;8(2):140-50.

5. Samson L., King S. Evidence-based guidelines for universal counselling and offering of HIV testing in pregnancy in Canada. CMAJ 1998; 158(11):1449-57.

6. Jackson J.B., Macdonald K.L., Cadwell J., et al. Absence of HIV infection in blood donors with indeterminate western blot tests for antibody to HIV-1. N Engl J Med 1990;322(4):217-22.

7. Doran T.I., Parra E. False-positive and indeterminate human immunodeficiency virus test results in pregnant women. Arch Fam Med 2000;9(9):924-9.

8. Burke D.S., Brundage J.F., Redfield R.R., et al. Measurement of the false positive rate in a screening program for human immunodeficiency virus infections. NEngl J Med 1988;319(15): 961-4.

9. Magee L.A., Murphy K.E., Von Dadelszen P. False-positive results in antenatal HIV screening. CMAJ 1999; $160(9): 1285$.

10. Alexander T.S., Lee J., Yen-Lieberman B. Incidence of human immunodeficiency virus antibody in a prenatal population at a community hospital. Clin Diagn Lab Immunol 1999;6(1):140-1.

11. Celum C.L., Coombs R.W., Jones M., et al. Risk factors for repeatedly reactive HIV-1 EIA and indeterminate western blots. A population-based case-control study. Arch Intern Med 1994;154(10):1129-37.

12. Midthun K., Garrison L., Clements M.L., et al. Frequency of indeterminate western blot tests in healthy adults at low risk for human immunodeficiency virus infection. The NIAID AIDS Vaccine Clinical Trails Network. J Infect Dis 1990;162(6): 1379-82.

13. Jackson J.B., Balfour H.H.Jr. Practical diagnostic testing for human immunodeficiency virus. Clin Microbiol Rev 1988; $1: 124-38$.

14. Dock N.L., Kleinman S.H., Rayfield M.A., et al. Human immunodeficiency virus infection and indeterminate western blot patterns. Prospective studies in a low prevalence population. Arch Intern Med 1991;151(3):525-30.

15. Da Silva J.M., Correa J., Terto V. Overcoming prejudice. AIDS Action 1998;2(39):5.

16. Nicoll A., Mcgarrigle C., Brady A.R., et al. Epidemiology and detection of HIV-1 among pregnant women in the United Kingdom: results from national surveillance 1988-96. BMJ 1998;316(7127):253-8.

17. Barbacci M., Repke J.T., Chaisson R.E. Routine prenatal screening for HIV infection. Lancet 1991;337(8743):709-11. 